\title{
¿Quién soy hoy? La trasformación profesional desde la reflexión en la acción con madres
}

\author{
Who am I today? \\ Professional Transformation Resulting from Reflections on Working with Mothers
}

\author{
Evelyn Jiménez-Salas ${ }^{7}$ \\ Ministerio de Educación Pública \\ Centro de Educación Especial de Atención integral de Goicoechea \\ San José, Costa Rica \\ evelyn.jimenez.salas@gmail.com
}

Recibido 3 de noviembre de 2013 • Corregido 13 de octubre de 2014 • Aceptado 22 de noviembre de 2014

\begin{abstract}
Resumen. El artículo cuenta mi historia personal durante el paso por la educación superior y parte de las vivencias e ideas que marcaron mi construcción como terapeuta ocupacional y, posteriormente, mi reconstrucción y deconstrucción durante el paso por el postgrado en Pedagogía de la Universidad Nacional, el cual converge en mi propia transformación junto a las participantes del proceso de investigación acción participativa y los acompañantes teóricos que conducen y asisten esta vivencia. Es vital contextualizar lo escrito en este artículo, debido que solo conociendo y descomponiendo la estructura del lenguaje desde donde fue redactado es que el lector logrará descubrir las diferentes significaciones de estas palabras. Este artículo describe el camino que conduce a la ruptura paradigmática que vivo, teniendo como profesión base la terapia ocupacional y siendo participante activa en un proceso de investigación-acción, con un grupo de 15 familias representadas en su mayoría por madres con un niño o una niña con necesidades educativas especiales que viven un proceso de trasladado a otro centro educativo. La investigación implicó un trabajo en conjunto, en donde se mezclaron las experiencias más saberes del grupo de madres que han vivido el proceso de traslado, con los del grupo que estaba por vivirlo y con los de la investigadora. Se tuvo claro, desde el inicio, que estas condiciones son determinantes aunque no las únicas que protagonizan dicho proceso en nuestro centro de educación especial. Parte importante del proceso consistió en la posibilidad de vernos reflejadas, las unas a las otras, en las experiencias y vivencias, con lo cual se validaron sentimientos, formas de procesar y de resolver problemas, producto del exponernos a las exigencias de lo cotidiano.
\end{abstract}

\footnotetext{
${ }^{1}$ Licenciada en Terapia Ocupacional (Universidad Santa Paula). Ha trabajado como terapeuta ocupacional en el Hospital Nacional Psiquiátrico Pbro. Manuel Antonio Chapuí y en el Equipo Base del Centro de Atención Integral Para Adultos con Discapacidad del antes conocido Hogar Luz (Aldeas SOS). Ha realizado cursos de actualización profesional en instituciones como el Instituto de Neurociencias de Colombia, el Colegio de Terapeutas Ocupacionales en México, la Organización de los Estados Americanos (OEA), el Ministerio de Educación Pública de Costa Rica en coordinación con el Centro Nacional de Recursos para la Educación Inclusiva (CENAREC), la Universidad Santa Paula, la Universidad Nacional y otras. Se ha desempeñado como docente en diferentes universidades del país como la Universidad Nacional, la Universidad Santa Paula, la Universidad Autónoma de Centroamérica y la Universidad Americana. Actualmente labora en el Centro de Educación Especial de Atención Integral de Goicoechea y, además, es egresada de la Maestría Profesional en Pedagogía con Énfasis en Desarrollo y Atención Integral de la Primera Infancia de la Universidad Nacional de Costa Rica.
} 
doi: http://dx.doi.org/10.15359/ree.19-1.18

URL: http://www.una.ac.cr/educare

CORREO: educare@una.cr

Palabras claves. Acompañamiento familiar, deconstrucción, resiliencia, investigación-acción, terapia ocupacional, primera infancia.

Abstract. The article presents my personal story during my time in higher education and some of the experiences and ideas that marked my preparation as an Occupational Therapist, as well as my construction and reconstruction during my time in the Graduate Program in Pedagogy at the National University (Costa Rica); which resulted in my own transformation that I experienced along with the subjects of a participatory action research process and the theoretical references that framed this experience. It is vital to contextualize this article because it is only knowing and decomposing the structure of the language from which it was written that the reader will be able to discover the different meanings in these words. This article describes the paradigm shift that I experienced while working as an Occupational Therapist and being an active participant in an action research process with a group of 15 families, mostly represented by mothers with a child with special educational needs in the process of being transferred to another educational center. The research project implied working jointly, blending the experiences and knowledge of those mothers who have already been through the transfer, with the experiences of those mothers about to do it, in addition to those of the researcher. It was clear from the beginning that these conditions are crucial but are not the only ones that play a role in our Special Education Center. An important part of the process was the possibility to see ourselves reflected on each other's experiences, which helped validate feelings and ways of processing and solving problems, as a result of exposing ourselves to everyday demands.

Keywords. Family accompaniment, deconstruction, resilience, action research, occupational therapy, early childhood.

¿Quién iba a decir hace más de 15 años que en este momento estaría escribiendo estas páginas y, especialmente, con estas palabras? Recuerdo ese día como si fuese hoy; era la primera clase del primer cuatrimestre y mis emociones y expectativas, con respecto a la vivencia que tendría en el tránsito por la malla curricular de la carrera estaban por los cielos.

He de aclarar que cuando realicé mi proceso de matrícula en la Universidad Santa Paula fue para formarme en otra profesión, pero ese día fue determinante: tomé una decisión que ha influenciado ampliamente mi vida. La profesora encargada de la primera clase que recibía fue interrumpida por la Directora de la Escuela de Terapia Ocupacional; y esta, deseosa por transmitir su pasión por la carrera, se deleitó explicando a los estudiantes del grupo qué era, qué hacía y qué se necesitaba para ser un terapeuta ocupacional. No lo pensé dos veces, porque la pasión con que esta mujer habló durante escasos cinco minutos, y lo multifacético de esta nueva opción profesional me convencieron de inmediato para trasladar mi nombre, mi energía y mi proyecto de vida laboral, a esta maravillosa forma de ofrecer oportunidades a las personas con quienes trabajo. Más adelante, como menciona Meyer, citado por Schwartzerberg (1998) y con la teoría como sustento, pude entender que mi rol como terapeuta ocupacional consiste en proporcionar oportunidades más que prescripciones. Y de esta forma es que el terapeuta ocupacional promueve diferentes espacios para ser, para hacer, para planear, para crear y para aprender en lo cotidiano. 
Fueron cuatro años de estudio y de aprendizaje teórico-práctico en terapia ocupacional. De construir imágenes mentales que asociaran toda esa información con la forma en que deben y pueden hacerse muchas de las diferentes intervenciones con las personas que reciben estas atenciones. De percibir desde la "formación", y esto debido al paradigma que influenciaba el momento de mi paso por la universidad, que la mayor parte de la responsabilidad sobre la maximización de la independencia y el mejoramiento en la calidad de vida de las personas con discapacidad que hacían uso de mis servicios, yacía sobre mí y mis destrezas como profesional. Estas percepciones se transformaron en ideas $y$, estas se consolidaron a lo largo de los años estructurando el sistema de razonamiento profesional $y$, hasta personal, que ha dirigido mis acciones directas hacia las personas, la familia, otros profesionales y la comunidad.

\section{El tránsito por la carrera y su educación de base humanista}

La terapia ocupacional es una profesión con bases humanistas que conquistó mi atención y energía, ya que desde sus bases profesa un claro respeto por el sistema de valores del individuo. Yerxa, citada por Schwartzerberg (1998) explica que mediante la utilización de sus destrezas y conocimiento, la persona terapeuta ocupacional logra ofrecer a la gente una variedad de posibilidades que constituyen su realidad externa, pero que al fin y al cabo es esta quien elige cuál le produce mayores beneficios; parte importante en el proceso de atención centrada en las necesidades del individuo.

Aunque conozco muchas de las teorías y modelos que organizan y administran la profesión, aseguro desde la humildad que no las conozco o domino todas; por el contrario, debido a mi labor en pediatría y especialmente en el ámbito educativo, desde hace años me he inclinado por actualizaciones profesionales que se dirijan a esta población en la mencionada área ocupacional.

Al participar en cada uno de los cursos universitarios y concluir satisfactoriamente el programa de estudio una cree que el proceso de aprendizaje ha concluido y que ya se sabe todo lo que se debe saber para ejercer profesionalmente. Esta primera ruptura entre lo que creía que era y lo que realmente es tiene su inicio en el momento en que realizo mis prácticas clínicas profesionales. Un hecho trascendental permite el análisis tanto de mi posición como profesional frente a las necesidades de las personas que reciben mis servicios, como del trabajo conjunto con otros profesionales. Según Schwartzberg (1998), Adolf Meyer en la década de los veintes hablaba sobre la necesidad de aptitudes, talentos y personalidades "raras" que faciliten adentrarse en la dinámica de las personas, familias y comunidades en la práctica cotidiana de la terapia ocupacional y, que se hace necesario tener confianza en la propia naturaleza y mostrar a los demás qué hacer consigo mismo.

Pero esta idea se quebranta cuando llega el momento de hacer una intervención directa con las personas sujetos de atención terapéutica, en la cual se busca solventar o resolver sus 
doi: http://dx.doi.org/10.15359/ree.19-1.18

URL: http://www.una.ac.cr/educare

CORREO: educare@una.cr

necesidades en las diferentes áreas ocupacionales de educación, ocio, trabajo, participación social y actividades de la vida diaria; ya que las teorías e información a las que tuvimos acceso mientras cursábamos el bachillerato o la licenciatura de la carrera no reflejaban la realidad de nuestra cultura, idiosincrasia y nuestros contextos.

Y es que, según Cohn (1998), durante este periodo de transición entre los roles de estudiante a profesional, existe un proceso de cambio de estructura y de sentido de una misma. Mas se hace necesario decir, también, que durante este cambio la experiencia de desequilibrio e incertidumbre puede convertirse en una gran oportunidad para crecer y desarrollarse integralmente. Fue un momento apropiado para modificar la forma como me percibía a mí misma y al mundo, y esto influyó directamente en mi accionar y en la manera de relacionarme con las demás personas.

\section{Los paradigmas y modelos de intervención en el ejercicio profesional}

Existen realidades a las que una persona se expone en la cotidianidad que no necesariamente hacen propias, debido a las cegueras que presentan por "formación" en la carrera. Esto lo menciono desde la reflexión personal, la vivencia y la convivencia (Maturana, 2007). Tomando como referencia esta interpretación, me devuelvo en el tiempo para mirarme en mi proceso académico y práctico con supervisión; y descubro que existen vacíos. Esta apreciación está relacionada con mi necesidad de contar con mayor cantidad de experiencias prácticas coherentes con los diferentes marcos de referencia y modelos que organizan el ejercicio y las bases de la terapia ocupacional contemporánea, ya que la oportunidad de integrar los conocimientos teóricos a la aplicación, de manera progresiva en demandas y pluralidad de poblaciones, ha sido considerada y reconocida desde siempre como vital (Cohn, 1998).

Parte esencial de la práctica profesional en terapia ocupacional es acercarse a la realidad del usuario para evaluar a la persona en su dinámica cotidiana y establecer, junto a ella qué es lo que se va a resolver y cuál será la manera o maneras de hacerlo. En este acontecer complejo y demandante de la realidad, emerge la necesidad de renovar mi quehacer y ofrecer otras oportunidades a los niños y las niñas del centro educativo en el que laboro. La búsqueda de ofertas de actualización profesional, que me facilitaran más y mejores herramientas para lograr un desempeño más coherente en mi trabajo, me llevó a acercarme a diversas entidades educativas, entre ellas la Universidad Nacional. Fue de esta manera y casi sin darme cuenta, que me encontraba asistiendo a los primeros cursos de la Maestría en Pedagogía con Énfasis en Atención y Desarrollo de la Primera Infancia, marco en el cual desarrollo mi investigación. 


\section{La vivencia del proceso de construcción investigativa}

El camino recorrido en la maestría tuvo diferentes paisajes, climas y topografía. Cada uno de los cursos funcionaba como una pieza que, aunque no siempre encajan a la perfección, han logrado darle sentido a la imagen que en conjunto se espera que proyecten. El eje transversal del proceso ha sido transformar la manera en que percibimos ynos desempeñamos profesionalmente, la forma en que escuchamos al otro, validamos lo que siente y lo acompañamos maximizando su participación en la toma de decisiones y en su desempeño de las actividades cotidianas.

Esta intencionalidad, encausada hacia la promoción de cambio de pensamiento y acción, prevalece en la mayor parte del recorrido. El andar se caracteriza por la construcción conjunta de ideas, conceptos, imágenes y métodos que dan vida a una nueva forma de concebir la realidad, propiciando la autonomía y el autodesarrollo profesional (Latorre, 2003). Y es en esta forma diferente de compartir, descubrir y aprehender con los otros que la participación propia es activa, consciente y decidida, en un intento por reinventarnos a nosotras mismas y nuestras prácticas.

El proceso de crecimiento al que hago referencia tiene diversos afluentes y estos confluyen en uno que contiene la mayor parte de la energía y la atención: un proyecto de construcción investigativa conjunta en el que comparto espacios de acompañamiento con un grupo de quince madres, que estaban viviendo situaciones particulares debido al traslado de uno de sus hijos o hijas con necesidades educativas especiales hacia otro centro educativo y todo lo que un proceso como este puede generar en temas de autonomía, relación con sus iguales, aceptación social y desempeño escolar.

\section{¿Cómo inició todo?}

No inició en un espacio geográfico sino en el imaginario. Empezó como conceptos, ideas, expectativas. No con algo en concreto, pero sí con todas estas preconcepciones, imágenes y vivencias como materia base y que forman parte de los productos de nuestro diario vivir y de las experiencias laborales previas. Es claro para mí que el contexto en el cual se desarrolla este proceso incluye nuestras historias y realidades; y todo esto se amalgama dentro de la convivencia y el compartir.

En el momento en que una persona, particularmente un niño o niña, nace con alguna deficiencia que disminuye su capacidad o la adquiere; su red social se impacta, con especial intensidad su familia, colocada en una situación que demanda maximizar su capacidad de resiliencia. La situación de crisis se prolonga durante un lapso en el que podrán producirse o no daños en la socialización, en la disponibilidad de recursos materiales y económicos, en los vínculos afectivos, en la vivencia de la cotidianidad, en la confianza en el núcleo familiar, en la integración y en la participación comunitaria (Federación Española de Daño Cerebral [FEDACE], 2009). 
doi: http://dx.doi.org/10.15359/ree.19-1.18

URL: http://www.una.ac.cr/educare

CORREO: educare@una.cr

En mi cotidianidad, como parte de un equipo interdisciplinario encargado de la atención de las necesidades de los niños y las niñas del nivel de preescolar en el centro en el cual laboro, la perseverancia, la empatía y la actitud profesional positiva hacia el proceso de inclusión educativa marcan la diferencia en el manejo y el resultado obtenido por cada uno de los niños y niñas que van a trasladarse a otro centro educativo. Son determinantes en todo momento, la coordinación asertiva y oportuna entre los actores principales del proceso, en este caso los niños y las niñas, sus familias y los profesionales de los centros educativos. Es claro que los esfuerzos aislados desencadenan frustración colectiva, lo cual se ve reflejado en el desempeño de nuestros niños y niñas.

Chávez (2003) expone que la no coordinación dificulta, en primer término, comprender al niño, sus necesidades y los contextos en los cuales interactúa y; en segundo término, entenderse entre profesionales. En este caso debe considerarse la coordinación como prioridad, para facilitar a todas y todos los involucrados compartir un mismo lenguaje, suficiente para cooperar y colaborar en la construcción de un niño o niña que sea percibido por los demás y por sí mismo como un ser humano holístico, favoreciendo su inclusión dentro de los contextos familiar, social y cultural más próximos.

Para cumplir con la misión y visión de nuestro centro educativo interesa que este acompañamiento hacia la inclusión de nuestros niños y niñas en otros ambientes educativos que no pertenecen a la educación especial se dirija a proveer variadas herramientas y oportunidades a las personas encargadas de los niños y niñas, que les permitan incidir en la construcción de la autonomía, autodirección y calidad de vida de estos, siendo un proceso que tiene un tiempo de transformación singular y propio (Maturana y Varela, 2004).

En general pensamos que estos apoyos ligados a la transición de los niños y niñas a otras instituciones que pertenecen al sistema educativo nacional, dirigidos a las personas encargadas, provienen de la intervención de los equipos interdisciplinarios. Por esta razón, cuando algunas de las madres de estudiantes del centro exponen su interés en compartir sus percepciones sobre las experiencias que obtuvieron durante el cambio de institución educativa, descubro la oportunidad de socializar y hacer partícipes a otras madres, que se iniciaban en el proceso de traslado desde una nueva mirada, la de la vivencia. Esto significó propiciar distintos momentos, pero con una diferente perspectiva, la de las madres con sus hijos e hijas fuera del centro de educación especial. El compartir sus herramientas y construcciones a lo largo de los años con aquellas madres que están iniciando el tránsito de la inclusión en otro centro educativo se vuelve trascendental y el objeto de investigación de este proceso de acción-reflexión.

Chávez (2003) propone que permitir a cada actor dentro del proceso escuchar otros argumentos que clarifican, cuestionan y ubican los límites del propio saber y quehacer, dejando a un lado la seguridad que brinda un saber supuestamente obtenido de las formas o maneras que le son familiares, es una manera de transformar. En este contexto puedo determinar piezas que se unen para crear distintos paisajes con actores, escenarios y argumentos articulados en 
pro de la inclusión exitosa de los estudiantes y las estudiantes en otros centros educativos. Estas piezas fundamentales son las madres de estas familias. Hablo de mujeres que han asumido la mayor parte de la responsabilidad, si no es que toda, sobre la manutención, la salud y la educación de los miembros de cada uno de estos núcleos sociales que representan. Hablo de mujeres jefas de hogar que han asumido frente a la sociedad, la responsabilidad de velar por el desarrollo integral de hijos o hijas, de nietos o nietas. Hablo de mujeres trabajadoras tanto en su hogar como en otros entornos, que valientemente decidieron aventurarse juntas en un viaje del cual no teníamos alguna certeza más de que estábamos ahí para mejorar y crecer.

Es con esta idea que emerge, como premisa de partida del proceso, que la manera más exitosa de aproximarse a la realidad es con la persona que se encuentra más cercana a esta, lo cual resulta ser una forma amena y conocida que facilita la confianza y la comodidad en un proceso de intercambio; como expresa Bucay (2009) en su cuento El temido enemigo, "y como siempre, estar cerca del que sabe vuelve al que no sabe más sabio" (p. 14).

Y es en este punto en donde surge la posición de las madres que ya han atravesado el proceso de traslado de su hijo o hija, cuando todo el panorama cambia, ya que siempre la información ha venido desde mi persona en mi rol de terapeuta ocupacional. Y se hace necesario aclarar que no se trata solo de un proceso de terapia ocupacional, es más complejo porque se trata de un asunto de la vida. Integra lo vivido en sus dificultades y retos, en sus alcances y posibilidades. Se trata de dar a las madres voz, para compartir sus vivencias desde la emocionalidad y el conocimiento. La madre que ha vivido el proceso puede compartir la certeza de que sí se puede y que la experiencia es positiva desde la construcción que ha realizado durante el hacer y rehacer. De que el acompañamiento es importante hasta en las actividades más sencillas y cotidianas. De que la angustia es válida lo mismo que la incertidumbre. De que todo lo que perciben, sienten y les emociona, es válido (Espinosa y Londoño, 2010).

Se trata de aprovechar los conocimientos del conjunto, el de las madres, el mío técnicoprofesional, el vivencial desde el amor y la experiencia. He partido del entendido de que escuchamos con mayor empatía a alguien que ha vivido procesos similares a los nuestros. Esta fue mi estrategia, mi metodología. Maturana (2007) afirma que el lenguaje, el expresar lo que se lleva adentro, permite que cada persona reflexione sobre su ser, su saber y su quehacer, tomando conciencia sobre sí mismo y sí misma al describirse como persona; haciendo de su circunstancia algo real, válido y con sentido.

\section{El protagonismo de las madres}

Los espacios de conversación grupales buscan ser herramientas para juntas resolver retos, analizar las diferentes formas de pensar y el accionar frente a las necesidades de los niños y las niñas. Son espacios para la generación y construcción personal y grupal, donde terapeuta y madres se comunican de manera horizontal, familiar y empática. Es un espacio de convivencia 
doi: http://dx.doi.org/10.15359/ree.19-1.18

URL: http://www.una.ac.cr/educare

CORREO: educare@una.cr

dialógica, que propicia que la mirada gire hacia los puntos de encuentro y que tiene como matices aprender a escuchar, respetar al otro y renunciar a juzgar (Espinosa y Londoño, 2010).

Este proceso de madres que apoyan a madres, se observa, analiza, construye y reconstruye desde la investigación acción, la cual encuadra las formas en que se desarrollaron las actividades y alcanzaron los propósitos. Latorre (2003) argumenta que este modelo de investigación implica la colaboración entre las personas participantes, quienes se involucran en cada una de las fases del proceso caracterizado por la comunicación simétrica que coloca a las personas en una relación de iguales con respecto de la aportación a la investigación.

El proceso de traslado e inclusión educativa de los estudiantes que asisten al centro de educación especial en el que trabajo, hacia otros centros educativos se ha desarrollado durante muchos años y el servicio de terapia ocupacional ha formado parte activa de él. Durante los últimos tres años se ha acompañado a las madres en diferentes temáticas y estrategias que provean a los niños y niñas mayor autonomía en los diferentes contextos en los cuales se desenvolverán. Esta ha sido la primera ocasión en que estos espacios de construcción conjunta fueron liderados tanto por las madres que han vivido la experiencia previamente, como por la terapeuta, durante un proceso cualitativo de interacción social en un ambiente escogido por ambas partes y que favoreció el intercambio y la recolección de información de forma sistemática y no intrusiva (Taylor y Bogdan, 2000).

En las intervenciones anteriores, la dinámica de los encuentros se centró en que la terapeuta proporcionara diferentes ideas que resolvieran las necesidades en adaptaciones, ayudas técnicas, accesibilidad y estrategias para maximizar la autonomía y participación de los niños y las niñas en las diversas actividades de la vida diaria de los diferentes ambientes en los cuales se desenvuelven. Es decir, se buscaba que las madres de familia "aprendieran" diferentes técnicas, actividades, adaptaciones, entre otros; que son importantes para los niños y las niñas en este proceso de inclusión en otro centro educativo.

A partir de estas experiencias surgen las interrogantes: ¿Por qué se hace o debe hacerse ese traslado? ¿Por qué los niños y las niñas y sus familias deben dejar de asistir al centro, como principal recurso educativo? Existen muchas razones que justifican este tránsito, entre estas priorizamos la necesidad de que niños y niñas se enfrenten con retos diferentes a los cotidianos hasta ahora, como compartir el aula con más de 20 compañeros y compañeras, hecho que no se da en nuestro centro y representa una gran oportunidad para generar un repertorio amplio de conductas adaptativas dentro del contexto escolar; como exponerse a la exigencia y la competitividad sana en un ambiente educativo que promueva mayor participación, autodirección y autonomía en los niños y las niñas. Y es que aunque en el centro se trata de crear los espacios y los momentos para que algunas de estas condiciones u oportunidades se den, no son tan vívidas y rigurosas como las que están dentro de otros ambientes educativos en los cuales se desenvolverán. 
En esta ocasión un grupo de madres que estaban preparándose para hacer el traslado de sus hijos e hijas hacia otra institución educativa hicieron notar el interés por compartir sus inquietudes y construir en conjunto herramientas que facilitaran a cada quien el transitar por esta vivencia. Se manifiesta la necesidad de las madres de estar juntas para cooperar y edificar en conjunto, como afirma una de las participantes:

¿Por qué cuando yo estaba pasando eso no hicieron unos talleres que nos informaran? Es bueno que todos sepamos que ningún niño nace con un manual debajo del brazo, ninguno. $Y$ que ninguna mamá sabe ser mamá hasta que tiene a un hijo, eso es necesario decirlo.

Esta dimensión de colaboración y de participación del grupo de madres a lo largo de todo el caminar se traduce en el trabajo en equipo con diferentes personas que viven una misma realidad, creando mejores canales de comunicación hacia el resto de personas que se encuentran cerca de ellas y que facilitan y mejoran su relación con los otros y las otras; además de la propia realidad. Según Herrera (2008), en la investigación acción se exige la democratización de los roles y funciones de las personas participantes, y esta es una de las características que evidencia la horizontalidad del proceso vivido.

Las madres con mayor experiencia en el traslado a otro centro educativo se constituyen como protagonistas vitales en este accionar, en tanto ya han aprendido que se trata de un aprendizaje compartido entre profesionales, madres, niños y niñas. Y es que han sido las madres quienes, de manera creativa, por el amor y el compromiso que asumen hacia sus hijos e hijas, crean e innovan constantemente, aceptando, entendiendo y creciendo desde sus propios miedos e incertidumbres, como comenta una de las participantes:

Yo misma me decía que era yo la que le ponía frenos a mi hijo, yo lo limito de la capacidad que él tiene. Yo sé que él tiene una gran capacidad, pero a veces decía: "pobrecito". Ahora ese "pobrecito" se fue. Es más, ese "pobrecito" me enoja, porque uno no debe decirle a un niño así.

Freire (2006) agrega que lo importante radica en crear las posibilidades para la propia producción y construcción del conocimiento, así los saberes cotidianos de cada una de ellas son el material más valioso en este proceso de reflexión.

Fue determinante la manera sencilla y fluida en que logramos articular este espacio de intercambio de modo que promovió un rol protagónico verdadero por parte de las madres de familia. En este sentido, mi papel como facilitadora participante requirió apertura, empatía, humildad y flexibilidad donde todos y todas compartimos diferentes saberes y experiencias. Comúnmente, las madres depositan el lugar del saber en la profesional, y esto tiene origen en las ideas que van implícitas en las experiencias dentro del centro; debido a las instrucciones de 
doi: http://dx.doi.org/10.15359/ree.19-1.18

URL: http://www.una.ac.cr/educare

CORREO: educare@una.cr

docentes y terapeutas que señalan a las madres la guía para mejorar el desempeño funcional de su hijo o hija. Como personal del centro esperamos que las madres sigan las instrucciones, porque la experiencia y el conocimiento nos dicen cuáles estrategias seguir con cada niño o niña. Pero esta forma de abordaje es la que tratamos de flexibilizar durante los encuentros con las madres ya que la frase"soy la que les va a enseñar a ellas lo que tienen que hacer para que las niñas y niños sean independientes en el kínder" es una construcción personal basada en un modelo de atención que no involucra a las madres, a la familia, o a los niños y las niñas y que se ve transformada en cada momento de encuentro con ellas. Este rol "asumido" por las madres fue reflexionado ampliamente durante el compartir, en concordancia con lo expuesto por Herrera (2008) sobre la configuración del investigador como un nuevo tipo de profesional que se exige y es flexible en un marco que encierra un proceso de mejora permanente, que facilita una lectura crítica de la realidad y en el que el investigador trabaja activamente en el proceso de su transformación constante.

Mi papel por tanto es tan activo como el de las madres, somos un equipo. No soy yo quien tiene la verdad, entre todas construimos verdades. Mi relación con ellas tiene como fin proveerles ideas y algunas herramientas para resolver en lo cotidiano lo funcional, estas han sido complementadas, mejorados o modificadas por todas como grupo.

Esto no fue sencillo, ya que hubo que consensuar cuáles temáticas han sido y eran prioritarias de abordar durante los encuentros, determinar cuáles han sido las necesidades comunes para mejorar la independencia y participación de los niños y las niñas en actividades, contextos y ambientes en los cuales interactúan. Una condición importante de este andar es mirarse y mirar a los otros a través del compartir de las vivencias. A medida que el proceso avanza, confirmamos, como apunta Maturana y Varela (2004), que las personas participan cotidiana y continuamente en demandas de distintas complejidades y estabilidades, dependiendo del contexto en el cual se desenvuelvan; pero el resultado será, en la mayoría de las ocasiones, la congruencia natural de su aprendizaje.

Los hallazgos generados en los seis momentos de encuentro evidencian la necesidad de direccionar la energía hacia la perspectiva que tienen las madres sobre:

Las diferentes rutinas, que conforman la cotidianidad familiar. Organizan y distribuyen el tiempo de los miembros y guían los patrones que hacen funcionar de una manera determinada las relaciones entre los miembros.

Sorprenden las reflexiones de la madres acerca de la distribución del tiempo de familia, la dinámica que llevan diariamente y que facilita o no la buena comunicación, el acompañamiento solidario de todos los miembros o de algunos de ellos hacia las necesidades del niño o niña con discapacidad que forma parte de ese núcleo familiar. Existen puntos que se abordan durante las conversaciones sobre la cantidad de horas de trabajo en el hogar que no es reconocida y en pocas 
ocasiones es valorada; la atención de los otros hijos e hijas, las circunstancias de salud emergentes y las citas médicas que demandan energía y tiempo, separadamente de lo que dedican a otras responsabilidades en el hogar. Algunas frases de las madres que ilustran lo anterior:

$\mathrm{OM}^{2}$ :... Pero soy yo la que la atiende. $\mathrm{M}^{3}$ solo quiere que yo le haga las cosas y no mi hija.

EK ${ }^{4}$ : Pero no siempre puede ser así, porque usted también tiene que descansar. Imagínese que nosotras necesitamos un tiempo de relax. Yo estoy en la Junta de Educación y $\mathrm{VJ}^{5}$ no sabe que también está (risas). Pero uno necesita espacio para las cosas de uno. Gracias a Dios muchas personas de mi familia colaboran con $K^{6}$.

LC7: El caso es que en mi casa solo somos tres: mi esposo, mi hijo y yo. Pero aunque mi esposo llega del trabajo, ya él tiene cosas que colaborar con el cuidado de $C^{8}$. Él se queja pero yo le digo que el chiquito no es solo mío, entonces le cambia la ropa, el pañal, le da los medicamentos, para poder descansar yo.

OM: Se aprovechan (familiares) porque se atienen de que los chiquitos quieren solo con uno, entonces los mandan donde uno para que les hagan las cosas.

Lo diario, lo habitual o cotidiano para las madres, quienes viven en lo básico, en lo común a ellas: la dinámica de casa, escuela y para algunas, el trabajo, representan un esquema rígido de horas, actividades y demandas que tiene pocas posibilidades de romperse, modificarse 0 flexibilizarse. Y es este círculo de poco acompañamiento familiar y social el que lleva a las madres a sentir impotencia, frustración e incomodidad frente a la situación de hogar que tienen.

${ }^{2}$ OM: Esposa. Madre de un hijo y una hija. Abuela de una niña, M. La señora trabaja realizando oficios domésticos por horas fuera de su hogar.

${ }^{3}$ Nieta de OM, y tiene una condición motora que dificulta la percepción, el equilibrio y el uso coordinado de sus cuatro miembros en las actividades cotidianas.

${ }^{4}$ EK: Esposa. Madre de un hijo, K; la señora es miembro de la Junta Administrativa de ese Centro Educativo. La señora trabaja medio tiempo fuera del hogar.

${ }^{5}$ VJ: Madre de dos hijos, uno de ellos, J; tiene una condición motora que dificulta la percepción, el equilibrio y el uso coordinado de sus cuatro miembros en las actividades cotidianas. El niño se encuentra cursando el sexto grado en una escuela diferente al centro. La señora participa activamente en las actividades de la Junta Administrativa de un centro educativo.

${ }^{6}$ Hijo de EK, y tiene una condición motora que dificulta la percepción, el equilibrio y el uso coordinado de sus cuatro miembros en las actividades cotidianas. El niño se encuentra cursando el tercer grado en una escuela diferente al centro.

${ }^{7}$ LC: Esposa. Madre de un hijo, C. La señora se mantiene a cargo de su hogar y de su hijo C.

${ }^{8} \mathrm{Hijo}$ de LC, y tiene una condición motora que dificulta la percepción y uso coordinado de su hemicuerpo derecho en las actividades cotidianas. 
doi: http://dx.doi.org/10.15359/ree.19-1.18

URL: http://www.una.ac.cr/educare

CORREO: educare@una.cr

Las familias que viven realidades parecidas se complementan y acompañan. Las madres tienen muchos conocimientos, muchas experiencias, muchas ideas; pero parece ser que ellas no creen que esto sea acierto, aunque llevan la mayor parte de la responsabilidad y peso sobre la construcción del proyecto de familia.

La capacidad de resiliencia que ha generado cada quien durante el proceso y que puede hacerse notar en sus palabras. Una de las capacidades que todo ser humano posee, y que fue descubierta y reconocida por las participantes durante este proceso, ha sido la resiliencia. Existen diversas fuentes para acompañar este concepto, pero Espinosa y Londoño (2010) lo definen como "... la capacidad inherente que tienen las personas para afrontar y superar las adversidades internas o externas, protegerse, crecer y seguir proyectándose hacia el futuro, a pesar de las circunstancias o de los acontecimientos desestabilizadores" (p. 114). Y ha resultado importante en la dinámica de los encuentros con las madres entender que debido a que la resiliencia es una capacidad, es posible hacer uso de ella desarrollando algunas habilidades como las "competencias para resistir el estrés, superar situaciones de alto riesgo y sanar traumas" (p. 115). Algunas frases de las participantes se leen a continuación y en ellas se evidencia la forma en que fueron descubriendo su proceso de desarrollo de habilidades, el cual les permite utilizar su capacidad de resiliencia,

VJ9: ...ese fue uno de los mejores regalos de ese año, ver a mi hijo comiendo solo y bebiendo solo. Creo que uno mismo les pone los límites a los hijos, porque uno cree que se les va a caer la comida o a quebrar un vaso; y uno después se da cuenta de que sí pueden hacerlo y que lo importante era que lo intentaran. Uno tiene que dejarlos y quitarse los miedos uno mismo.

$\mathrm{SL}^{10}$ : Después yo pensé en respaldarme con ustedes; yo pensé: "lo que ellas me digan yo lo voy haciendo", si ellas me dicen "esto es para mejorar", yo lo hago. Y si él lo hacía de otra manera yo les decía que él lo había intentado pero lo había logrado de esa forma, entonces ustedes veían si esa era la mejor forma o si todavía él podía mejorar.

\footnotetext{
${ }^{9}$ VJ: Madre de dos hijos, uno de ellos, J; tiene una condición motora que dificulta la percepción, el equilibrio y el uso coordinado de sus cuatro miembros en las actividades cotidianas. El niño se encuentra cursando el sexto grado en una escuela diferente al centro. La señora participa activamente en las actividades de la Junta Administrativa de un centro educativo.

${ }^{10} \mathrm{SL}$ : Madre de 3 hijas y un hijo. El varón tiene una condición motora que dificulta la percepción y uso coordinado de su hemicuerpo derecho en las actividades cotidianas. El joven se encuentra cursando el octavo año en el colegio. La señora ya es abuela y se mantiene a cargo de su hogar y de sus hijas e hijo menores de edad.
} 
Estas madres son excelentes representantes de las personas que hacen frente a situaciones adversas, doloras y difíciles, y que viven transformando su pensamiento y su actitud mientras viven. Esto les ha permitido desarrollar una gran capacidad de resiliencia y construir cotidianamente estrategias para resolver desde una postura de humildad al reconocer que no lo saben todo y necesitan aprender con otras personas.

Otra frase que evidencia descubrimiento y da importancia a este proceso personal proviene de una participante diferente

$\mathrm{AA}^{11}$ : Entonces fueron dos en una. Se iba en el microbús llorando al kínder y lloraba las tres horas del período en el kínder. Y yo me dije que eso era algo que ambas teníamos que vivir, yo me quedaba llorando cuando se iba en la micro pero sabía que ambas éramos perseverantes y que eso se iba a acabar en algún momento, que teníamos que vivirlo. $Y$ nosotras no podemos detenerlos a ellos porque pensemos que es duro separarse de ellos. Y hay que aprender a lidiar con eso.

La posibilidad de colocar en palabras la vivencia y que esta haga eco en otras madres facilita el reconocimiento de la propia transformación para esta mujer. Para Toro (2012), "hay una mayor implicación y compromiso cuando expresamos algo de nuestro mundo más íntimo y personal, cuando compartimos experiencias y sentimientos que nos importan y nos marcan o han marcado especialmente" (p. 84).

VJ: Igual, creo que ya a mí me tocó hacer el cambio y cuando les toque a ustedes se darán cuenta de que no hay que tener temor porque hay mucha gente pendiente de los chiquillos, igual uno puede ir y preguntar.

El comentario de la madre es contundente sobre su proceso de transformación de pensamiento y accionar con respecto a la forma en que asume el proceso educativo de su hijo y los retos que esto significa tanto para el niño como para ella. Es importante considerar que el desarrollo de la capacidad para hacer frente a las dificultades de la vida, de superarlas y de ser transformados positivamente; requiere de tiempo y cada quien vive su proceso de forma única y distinta a la de los demás. Tener certeza de que la situación va a ser diferente, sin que esto quiera decir bueno o malo, le permite a las madres tener esperanza (Espinosa y Londoño, 2010).

\footnotetext{
${ }^{11}$ AA: Madre de una hija, quien tiene una condición motora que dificulta la percepción y el uso coordinado de sus miembros inferiores. La niña cursa el primer grado en una escuela. La madre trabaja como docente universitaria en una Universidad Pública.
} 
doi: http://dx.doi.org/10.15359/ree.19-1.18

URL: http://www.una.ac.cr/educare

CORREO: educare@una.cr

Los roles que viven en los diferentes contextos en los cuales se desenvuelven y que tienen resonancia en sus discursos. Existen prejuicios que vienen de la mano con el género y los roles que desempeñamos en la sociedad. Desde mi perspectiva, pareciera ser que estas madres traducen los hechos dentro de la dinámica familiar con frases como: "usted ya lo hace y lo hace bien, entonces, ¿para qué va a hacer otra cosa? Mejor siga haciéndolo".

$\mathrm{KS}^{12}$ : Le he dicho a mi esposo que hay días en los que yo quisiera coger esa moto para irme a trabajar yo y dejarlo solo en la casa con los chiquitos para que vea como es con ellos.

La percepción que tienen las madres participantes acerca de sus roles tanto en el proceso de su hijo o hija, como en el ambiente familiar, comunal o social incide en la forma en que se organizan, deciden y accionan diariamente. Les supone reconocerse, entenderse y aceptarse desde una perspectiva crítica y reflexiva sobre diferentes cuestionamientos sobre quién es, qué hace, qué piensa, qué siente, qué necesita, entre otros, que surgen durante los diferentes encuentros.

KS: Esto a uno le ayuda (los encuentros con las otras madres) porque uno de verdad es ZOILA (persona que hace de todo). Me tenía que operar y lo pospuse por temor de no tener alguien que cuide a mi hijo. Evado el dolor de la hernia en el ombligo diciendo que no tengo nada, por lo mismo, y me pregunto ¿qué hago con S?

Ha sido notorio, en el compartir de las actividades dentro y fuera del centro, durante las visitas que se realizan al domicilio y por la forma tan atenta en que se conducen las madres con sus hijos o hijas, que la mayor parte de la responsabilidad sobre temas de salud, de atención directa en las actividades de autocuidado, de recreación, educativas, entre otras; haya recaído sobre las madres; asunto que pareciera tener raíces muy fuertes en la crianza de ellas, ya que representa una parte del discurso que muchas mujeres escuchan durante muchísimos años en el seno de sus familias, y que está cargado de prejuicios o estereotipos basados en roles que "deberían" desempeñar las mujeres, como la idea de que la mujer es la única que tiene la capacidad de atender a los niños y niñas, o que no es necesario que la mujer estudie y tenga una profesión. Es una cuestión social y cultural, es una cuestión de género. La intensidad sobre este tema durante los encuentros con las madres tiene matices particulares debido a la diversidad que representaban las participantes, pero tomó gran importancia conforme expresaban las dificultades que vive cada quien para realizarse en otro rol que no sea el de cuidadora de su hijo o hija; para ello utilizaban diferentes formas para expresar su necesidad de comunicar esta situación de vida y su deseo de ser escuchadas y apoyadas por las demás (Toro, 2012).

12 KS: Esposa. Madre de dos hijas y tres hijos. Uno de los varones tiene una condición motora que dificulta la percepción y uso coordinado de su hemicuerpo derecho en las actividades cotidianas.. La señora se mantiene a cargo de su hogar y de sus hijos e hija menores de edad. 
Como Toro (2012) nos sugiere, vivimos estos encuentros desde las conversaciones e intercambios, como oportunidades en las cuales acogimos al otro como alguien que nos ayuda a descubrir y reconocer las posibilidades y limitaciones propias. Cada uno de esos espacios se convirtió en invitación, sugerencia, reto y regalo porque esos momentos se tornaron en ocasiones muy significativas para reconocernos en las otras y con las otras.

La manera reflexiva y asertiva en que las madres pueden compartir sus experiencias con otras hace la diferencia en este proceso; ya que la actitud y la energía con que se recibe la información depende de las maneras e historias personales de quien las cuenta. Al respecto, Maturana y Varela (2004) afirma que es necesaria la reflexión en un proceso que nos permite descubrir cómo conocemos, es un acto de volvernos sobre nosotros mismos y sobre nuestra mirada, una oportunidad singular de descubrir nuestras cegueras, y conocer que las certidumbres o certezas que damos por sentado y los conocimientos de los otros son respectivamente tan abrumadores y tan tenues como los nuestros.

En los encuentros la conversación, la reflexión y el compartir dan color a las imágenes que caracterizan las vivencias de cada quien y, de la misma forma, evidencian problemas de acceso a conocimientos técnicos, pero riqueza en construcciones asociadas a sucesos de la vida cotidiana y a la emocionalidad propia de la maternidad y la paternidad. Frases relevantes que lo evidencian son las siguientes:

$\mathrm{SR}^{13}$ : Pero no entiendo entonces, ¿qué es?, ¿qué estamos haciendo mal? Uno lo que deseara es que él se fuera desenvolviendo bien y que no vaya teniendo esas fallas para que lo chiquitos en el kínder no lo agarren como el tontito del aula.

$\mathrm{AE}^{14}$ : Pero él está muy bien para la edad, lo que necesita es soltarse un poquito. Un poquito de seguridad.

SR Que logre desenvolverse bien y que no lo agarren de su muñequita, porque cuando mi hija estaba en el kínder se la gorreaban y le quitaban la merienda y todo.

EJ ¡Québien que usted cuenta eso! Porque no tiene nada que ver que se tenga una condición " $X$ " para que se trate a una persona de esa manera.

${ }^{13}$ SR: Viuda. Madre de un hijo y una hija. Abuela de $\mathrm{R}$, un niño que tiene una condición motora que dificulta la percepción y uso coordinado de su hemicuerpo derecho en las actividades cotidianas. La señora se mantiene a cargo de su hogar y de su nieto.

${ }^{14}$ AE: Esposa. Madre de un hijo y una hija. La niña tiene una condición motora que dificulta la percepción y uso coordinado de su hemicuerpo derecho en las actividades cotidianas. La niña se encuentra en el grupo de materno infantil en otra escuela. La señora trabaja fuera de su hogar dando cursos de manualidades y tarjetería. Asiste a cursos formales del INA y otro instituto sobre estas áreas. 
doi: http://dx.doi.org/10.15359/ree.19-1.18

URL: http://www.una.ac.cr/educare

CORREO: educare@una.cr

Los encuentros abren un espacio para la honestidad y solidaridad, para las relaciones interpersonales basadas en el caminar conjunto en busca de soluciones para los obstáculos. Nos reconocemos en la diferencia de crianza, edades, intereses, criterios, personalidad, gustos y caracteres. Cada quien se mueve con fuerza propia e irradia su propia luz. En ese sentido somos personas únicas en la diversidad y reales en la medida que siempre nos encontramos presentes para hacer valer nuestra posición frente a algo, aunque esto represente exponer nuestros temores y angustias, exponer nuestras emociones. Me gustaría remitirme a Maturana (2002) quien nos dice que no podemos caracterizar al ser humano desde la razón:

Nos deja ciegos frente a la emoción, la cual queda desvalorizada como algo animal o como algo que niega lo racional. Es decir, al declararnos seres racionales vivimos una cultura que desvaloriza las emociones, y no vemos el entrelazamiento cotidiano entre razón y emoción que constituye nuestro vivir humano, y no nos damos cuenta de que todo sistema racional tiene un fundamento emocional. (p. 15)

Somos mujeres y hombres que han compartido una voz y un abrazo que pretende permanecer en el tiempo. Provenientes de realidades diferentes que se tocan, desde la percepción, el sentimiento y la emoción que nos identifican y nos transforman. Las emociones no son lo que comúnmente conocemos como sentimientos, Maturana (2002) menciona que desde lo biológico estas se traducen a disposiciones corporales dinámicas que definen los distintos dominios de acción en que nos movemos cotidianamente.

Existe una meta común hacia la que nos proyectamos con claridad, nos reconocemos en la necesidad que tenemos de mejorar el mundo que nos rodea y con nosotros, a los niños y niñas. Palpitamos con el mismo amor que sustenta a las familias, a nuestras realidades y por el cual siempre hemos estado dispuestos a mejorar la calidad de vida de los que son cercanos. Estamos seguras de las manos que nos acogen y apoyan en este proceso, esperamos que este compartir genere un entorno más apropiado a las necesidades de los niños y las niñas, ya que merecen ejercer el derecho a crecer en un ambiente equitativo y equiparado, y a desarrollar al máximo sus potencialidades en donde "la creatividad y la ternura sean necesidades vitales y elementos definitorios de los sueños de felicidad individual y social" (Assmann, 2002, p. 28).

\section{Mi lugar en el andar}

Al revisar mis posiciones (Freire, 2006) encuentro que he vivido esta oportunidad de acercarme y acercar a las familias para acompañarnos en este proceso de traslado de los niños y las niñas en varias ocasiones anteriormente. Ha sido necesario entender que he sido yo una de las que más se ha beneficiado con este repensar lo pensado, porque de alguna manera las 
madres ya han resignificado su realidad y es por esta razón que lograron comunicarla a las otras. Esta realidad tiene un lugar claro para ellas y, por esto, es que se les facilita colocar sus vivencias en palabras. Las madres tienen el poder de lo vivido y lo expresan en estos momentos de encuentro logrando compartir y reconstruir su historia.

Ha sido este proceso de revisarme continuamente el que me permitió encontrarme con percepciones, sentimientos y emociones, que desde la práctica profesional se encuentran en la gama de respuestas subjetivas o reacciones de contratransferencia, como menciona Schwartzberg (1998), y que deben ser reguladas para calificar de terapéutica una relación con alguien que requiera de mis servicios. El punto es que desde los esquemas sociales en los cuales ejercemos no es correcto "involucrarse", se hace necesario que el buen terapeuta ocupacional pueda entender sus vulnerabilidades y prejuicios para garantizar la neutralidad y la objetividad durante el proceso de atención.

Freire (2006) nos dice que "es pensando críticamente la práctica de hoy o la de ayer como puedo mejorar la próxima" (p. 40) y es este ejercicio uno de los que me llama a la reflexión como profesional, ya que contrario a no involucrarme con las personas con las que trabajo, es necesario hacerlo; pero de una manera crítica desde la historia que han vivido, desde las necesidades que enfrentan y más que todo, desde la capacidad para resolver y salir adelante, desde la resiliencia.

Existieron, dentro de mí, la angustia y ansiedad, especialmente cuando preparaba los encuentros con las madres, ya que tenía clara la necesidad de estas por comunicar lo que sentían y vivían, pero más claro tenía lo deseosas que estaban por ser escuchadas. Me asaltaban pensamientos que trataban de sabotearme a mí misma que fueron desapareciendo, y estos podrían resumirse en interrogantes traídas desde hace décadas por Freire (2007) quien nos cuestiona "cómo escuchar al otro, cómo dialogar, si sólo me oigo a mí mismo, si sólo me veo a mí mismo" (p. 61).

Cuando regreso al momento de los encuentros con las madres reconozco como determinante el proceso en sí y no solo el producto. La toma de conciencia de cómo me encontraba presente en aquello que estaba realizando me permitió vivir a plenitud los acontecimientos, facilitó el reconocimiento de su esencia, y esta reside en la idea de que quien los vive no debe buscar la perfección, porque cada quien tiene una construcción distinta sobre su significado (Toro, 2012).

Es importante para mí, como persona y como profesional, reconocer que el cúmulo de conocimientos y experiencias vividas a lo largo de mi vida no significa más que los de las demás personas. Ha sido toda una revelación el análisis de las conversaciones y sobre todo recuperar, como menciona Jara (1994), en cada encuentro con las madres, lo que ya saben sobre su experiencia, ya que de esta manera hemos descubierto que no teníamos certezas 
doi: http://dx.doi.org/10.15359/ree.19-1.18

URL: http://www.una.ac.cr/educare

CORREO: educare@una.cr

sobre lo que sabíamos, pero también se han revelado conocimientos de los cuales hablamos cotidianamente, pero que no registramos en categorías de importancia para otras personas, porque no hemos hecho el análisis consciente o evaluado la información que hemos procesado a través de lo experimentado. Y no es sino hasta que alguna de las madres menciona un hecho específico, como por ejemplo la forma en que le enseñaron a comer a su hijo o hija, que invita a hacer este análisis sobre lo que han vivido, lo que saben sobre eso vivido y cómo eso se traduce en experiencia y conocimiento; de esta manera, se reflexiona y se entiende que aunque cada quien vive un proceso diferente, la cotidianidad les exige colocar esa información en categorías para ser utilizada, posteriormente, o para ser parte de otra información más compleja.

Y es este círculo de pensamientos y reflexiones el que nos provee de tanto conocimiento que creíamos no tener, pero también el que nos ha obligado a construir los propios. Freire (2005) plantea que "no puedo pensar por los otros ni para los otros ni sin los otros" (p. 112) y entiendo, desde esta idea, que fue la manera en la cual gira la conexión entre las madres y mi persona durante los encuentros la que facilitó la expresión respetuosa y espontánea de las participantes desde una posición cómoda y segura. Existió gran afinidad en el grupo de participantes y fue propicia para que, en diferentes momentos, las lágrimas acudieran, y en algunas mujeres se hicieron presentes en mayor cantidad que en otras porque la solidaridad frente al dolor, la frustración o la felicidad de la otra tocó en lo más profundo de cada quien, moviendo sentimientos; ya que por más sencillos que fuesen esos eventos relatados tienen conexiones en la vida de las otras de manera conmovedora (Toro, 2012).

Ahora es claro que validar estas vivencias es importante y necesario para la existencia de equilibrio en la cotidianidad. Cada participante se encuentra de frente al espejo cuando ve a otra madre, la desconocida y la que ha vivido lo que vivo. Nos encontramos en pleno desarrollo y generalización de estos saberes. Celebramos la alegría de estar juntas, este es el principio de un camino hacia el cambio de actitud frente este reto de traslado, pero ahora se vislumbra el horizonte y el caminar se vuelve necesario y continuo.

Quiero llevar a cabo un propósito que pueda volverse común y me brinde la oportunidad de compartir con las demás personas lo mejor de mí misma. He reconocido necesaria la realimentación con las otras personas para transformarme y crecer. El tiempo de la angustia, la ansiedad y la incertidumbre ha quedado atrás porque el espejo en el cual hoy me miro, revela grandes oportunidades para cambiar; y siguiendo a Sosa en su canción "Cambia todo cambia" creo que...

Si es posible que cambie lo superficial, el modo de pensar, el clima y todo lo que está en este mundo... es posible que yo cambie, es más... no es extraño. Yo ya cambié. 
Revista Electrónica EdUCARE (EdUCARE EleCtronic JOURNAL) EISSN: 1409-4258 VOL. 19(1) ENERO-ABRIL, 2015: 333-352

doi: http://dx.doi.org/10.15359/ree.19-1.18

URL: http://www.una.ac.cr/educare

CORREO: educare@una.cr

\section{Referencias}

Assmann, H. (2002). Placer y ternura en la educación. Hacia una sociedad aprendiente. Madrid: Narcea.

Bucay, J. (2009). Cuentos para pensar. Buenos Aires: Editorial Océano exprés.

Chávez, R. (2003). Neurodesarrollo neonatal e infantil. Un enfoque multi-inter y transdisciplinario en la prevención del daño. México: Editorial Médica Panamericana.

Cohn, E. (1998). Educación para la práctica profesional, socialización profesional. En H. Hopkins y H. Smith (8 ${ }^{\mathrm{a}}$ ed.), Terapia ocupacional (pp. 12-19). Madrid: Editorial Médica Panamericana.

Espinosa, M. E. y Londoño, P. (2010). Creciendo juntos. Un libro para fomentar la autonomía. Bogotá: USTA.

Federación Española de Daño Cerebral (FEDACE). (2009). Familias y daño cerebral adquirido (Colección Cuadernos FEDACE sobre daño cerebral adquirido). Madrid: Editorial FEDACE. Recuperado de http://fedace.org/wp-content/uploads/2013/09/9 familias y DCA.pdf

Freire, P. (2005). Pedagogía de la Esperanza. Buenos Aires: Siglo XXI Editores.

Freire, P. (2006). Pedagogía de la autonomía. Saberes necesarios para la práctica educativa. México: Siglo XXI Editores.

Freire, P. (2007). Cartas a quien pretende enseñar (4ª reimp.). Buenos Aires: Siglo XXI Editores.

Herrera, J. (2008). La investigación-acción. Recuperado de http://juanherrera.files.wordpress. com/2008/11/investigacion-accion.pdf

Jara, Ó. (1994). Para Sistematizar Experiencia: Una propuesta teórica y práctica. San José, Costa Rica: Alforja.

Latorre, A. (2003). La investigación acción: Conocer y cambiar la práctica educativa. Barcelona: Graó.

Maturana, H. (2002). Emociones y lenguaje en educación y política (11 ${ }^{\mathrm{a}}$ ed.). Santiago: Dolmen Ediciones.

Maturana, H. (2007). Transformación en la convivencia. Santiago: Editorial J. C. Editor.

Maturana, H. y Varela, F. (2004). El árbol del conocimiento. Bases biológicas del entendimiento humano. Buenos Aires: Lumen Humanitas. 
REVISTA ELECTRÓNICA EDUCARE (EDUCARE ELECTRONIC JOURNAL) EISSN: 1409-4258 VOL. 19(1) ENERO-ABRIL, 2015: 333-352

doi: http://dx.doi.org/10.15359/ree.19-1.18

URL: http://www.una.ac.cr/educare

CORREO: educare@una.cr

Schwartzberg, S. (1998). Instrumentos de práctica. En H. Hopkins y H. Smith (8a ed.), Terapia ocupacional (pp. 269-274). Madrid: Editorial Médica Panamericana.

Taylor, S. J. y Bogdan, R. (2000). Introducción a los métodos cualitativos de investigación. La búsqueda de significados ( $3^{\circ} \mathrm{ed}$.). Barcelona: Paidós.

Toro, J. M. (2012). Educar con "co-razón" (2a ed.). Bilbao: Desclée de Brouwer.

\section{(6) Cómo citar este artículo en APA:}

Jiménez-Salas, E. (enero-abril, 2015). ¿Quién soy hoy? La trasformación profesional desde la reflexión en la acción con madres Revista Electrónica Educare, 19(1), 333-352. doi: http://dx.doi.org/10.15359/ree.19-1.18

Nota: Para citar este artículo en otros sistemas puede consultar el hipervínculo "Como citar el artículo" en la barra derecha de nuestro sitio web:

http://www.revistas.una.ac.cr/index.php/EDUCARE/index 